\title{
Rubrics and Academic Performance in English as a Foreign Language Teaching: Assessing Writing Tasks
}

\author{
Monica Narvaez, Ms. \\ Unidad Educativa Miguel Angel León Pontón, Ecuador. \\ Edison Salas, PhD
}

Escuela de Ecoturismo y Escuela de Ingeniería Forestal de Escuela Superior Politécnica de Chimborazo, Ecuador.

Secretaria Nacional de Ciencia Tecnología e Innovación SENESCYT, Ecuador

Elsa Basantes, Ms. C.

Escuela de Finanzas, Escuela Superior Politécnica de Chimborazo, Ecuador.

Nancy Rodriguez, Ms.C.

Escuela de Ecoturismo y Escuela de Agronomía de la Escuela Superior

Politécnica de Chimborazo, Ecuador.

Maria Escobar, Ms.C.

Centro de Idiomas, Escuela Superior Politécnica de Chimborazo, Riobamba, Ecuador

Doi:10.19044/esj.2019.v15n17p46 ～$\quad$ URL:http://dx.doi.org/10.19044/esj.2019.v15n17p46

\begin{abstract}
Using rubrics in foreign language teaching has become a popular procedure among academics around the world. Rubrics are useful tools to improve educational in-class processes, as well as, to assess students' learning outcomes. This study aims to determine whether the application of rubrics as an assessment tool influences eighth-grade foreign language students' Academic Performance. A diagnostic survey was applied to the teachers of the foreign language department at the high school to determine which assessment tools were used to assess and grade students' writing class work. Twenty-eight students of eighth grade, classroom " $\mathrm{D}$ " (octavo año de educación básica class "D") and foreign language teachers of Unidad Educativa Colegio Militar N ${ }^{\circ} 6$ "Combatientes de Tapi (UECMCT), Riobamba, Ecuador, participated in the study. The Academic Performance data of the students was collected during the second term of the second five-month school period (quimester) and analyzed through figures and tables, where a written activity was assessed without the application of a rubric. The results of this first students' performance assessment showed that many students were not proficient in learning. Subsequently, an assessment rubric was elaborated and applied as an
\end{abstract}


evaluation instrument of a written activity during the third term of the second quimester. In this opportunity, as a result, a large number of students improved their performance and achieved the expected learning outcomes. The application of this assessment tool not only enhanced the Academic Performance of the students but also allowed the teacher to facilitate the assessment process.

Keywords: Rubrics, academic performance, writing activities, EFL, assessment

\section{Introduction:}

Evaluation constitutes a critical factor in educational processes; it seeks to improve the teaching-learning process regarding educational assessment for quality education, which, in turn, impacts academic performance. Many scholars have documented that the use of rubrics can have a positive influence on performance and learning (Panadero, Alonso-Tapia, \& Reche, 2013). In this context, the need to evaluate whether the application of rubrics influences students' academic performance arose because it is essential for educators, in our educational setting, to have proper assessment tools containing a set of specific criteria to allow teachers and students make judgments about how written activities are evaluated. The study was carried out at Unidad Educativa Colegio Militar No6 "Combatientes de Tapi" (UECMCT), Riobamba, Ecuador, during in the 2014-2015 school year, where 28 students of octavo año de educación básica class "D" (eighth grade, classroom " $\mathrm{D}$ ") and ten foreign language teachers participated in the study.

Aim

This study aims to determine whether the application of rubrics as an assessment tool influences eighth-grade foreign language students' Academic Performance.

\section{Specific objectives}

- To establish the assessment tools used by foreign language teachers.

- To determine the academic performance without the application of rubrics.

- To determine the academic performance after the implementation of rubrics.

- To compare academic performance results before and after implementation of rubrics. 


\section{Theoretical Framework Rubrics}

Rubrics in education refer assessment instruments which establish standards or instructions to evaluate student performance and guide student learning (Dickinson \& Adams, 2017; Fraile, Panadero, \& Pardo, 2017; Stiggins \& Chappuis, 2005). Rubrics comprise evaluation criteria and performance standards (Dawson, 2017; Dickinson \& Adams, 2017; Janssen, Meier, \& Trace, 2015) assisting both, teachers in grading specific characteristics of the task at hand, and students to understand what is expected from them. Specifically, rubrics are assessment tools, which facilitate the process of evaluation and reporting of student achievement by educators (Glickman-Bond \& Rose, 2006; Reddy, 2007). They are sets of detailed scoring guidelines which are essential for constructed responses and performance-based tasks (Glickman-Bond \& Rose, 2006; Reddy, 2007).

In a student-centered approach to assessment, rubrics have the potential to help students develop a vision of success and also learn to reliably judge the quality of their work (Fraile et al., 2017; Stiggins \& Chappuis, 2005). Testing students' performance using rubrics can help explain the performance quality standards and guide ongoing feedback about progress towards those standards (Black \& Wiliam, 1998; Brookhart, 2003; Panadero \& Jonsson, 2013; Stiggins $\&$ Chappuis, 2005). Moreover, rubrics also lend information to teachers, parents and other stakeholders interested in students, level of knowledge and new skills achieved (Dawson, 2017; Panadero \& Jonsson, 2013).

Concerning students' English skills performance, such as reading, writing, listening and speaking, rubrics offer useful guidelines for grading students' performance based on specific criteria (Sundeen, 2014). Those criteria are based on language features that students should master (Mianto, 2012). Therefore, rubrics can assist students in connecting learning (the study topic) and assessment (what is going to be assessed) by better understanding teachers' feedback which is more detailed, and more useful to identify and communicate what students have learned or and what they still need to learn (Glossary of Education Reform, 2014; Janssen et al., 2015).

There are four components to a rubric task description, task dimensions, a performance scale, and cell descriptions (Mianto, 2012). The task description, which usually is expressed in the syllabus, explains the task in detail and reminds grader what the task is about (Mianto, 2012). The task dimensions' layout and describe the parts of the task and are listed in the first column of the table (Mianto, 2012). They should be directly observable and in harmony with the learning outcomes. The performance scale identifies the levels of performance along each of the dimensions and is presented in the first row of the table. Scales should include three to five points. Too many scales points make it more difficult to differentiate between performance levels (Mianto, 
2012). Finally, cell descriptions prepare what each level of performance means for each dimension. These may include check boxes beside each element of the performance description in the cell. They help convey why the student is given a particular score (Mianto, 2012).

\section{Academic Performance}

Academic performance refers to results which indicate educational achievement (D'Alessio, Avolio, \& Charles, 2019; Fraile et al., 2017; Santos, 1998) obtained by students after hours of study, work capacity and their capacity of concentration (Santos, 1998). Academic achievement, as an indicator of students' level of learning, comprises a vast variety of educational outcomes (Fraile et al., 2017; Steinmayr, 2014; York, 2015). It is also the measure of the new capabilities developed by the students as a product of the developmental process. Performance indicators are very general, e.g., procedural and declarative knowledge acquired in an educational system, while other factors are more curricular-based, such as grades reached in an achievement test, and cumulative indicators such as academic degrees and certificates (Steinmayr, 2014).

In this context, given that academic performance is a vast subject, English textbooks often only address a few aspects of achievement such as enhancing academic success or some of its specific predictors (Hoy, 2007; Steinmayr, 2014). Consequently, academic achievement mainly represents performance outcomes, which in turn, shows the level achieved by students towards specific goals set for different activities within instructional environments, i.e., elementary school, college or university. Thus, academic achievement should be considered to be a multifaceted assemble comprising different domains of learning (Steinmayr, 2014).

Mushtaq and Nawaz Khan (2012) provide a thorough overview of the assessment of academic achievement where they argue that academic success is essential for every person. Academic achievement measured through standardized instruments, in different contexts, such as the SAT (Scholastic Assessment Test), can be a determinant for individuals to continue their education, e.g., to attend a university (Steinmayr, 2014). Furthermore, academic achievement is also crucial for the developing of a nation and its prosperity (Steinmayr, 2014).

\section{Importance of EFL/ ESL for Academic Performance}

Academic achievement is a crucial factor for young people's successful development within society (Regier, 2011). Successful adolescents have higher self-esteem, have lower levels of depression and anxiety, and are less likely to abuse alcohol and engage in substance abuse (Regier, 2011; Steinmayr, 2014). Also, students who perform well are better prepared to 
transition into adulthood and achieve professional and economic success (Regier, 2011; York, 2015). Furthermore, academic success influences selfesteem (Alves-Martins, Peixoto, Gouveia-Pereira, Amaral, \& Pedro, 2002). Successes and failures in academic achievement do not depend on only the differences in capabilities but that factors like thinking styles and evaluation also have an essential effect on educational outcomes Regier (2011). Therefore, satisfactory academic performance is vital in EFL/ ESL, because it aids to determine whether students have achieved the proposed cognitive and attitudinal educational objectives. And parents intimately involved in their children's education and family activities will perceive positive results, not only in the behavioral and academic areas but also in students' social interactions (Regier, 2011).

\section{Grading criteria for writing assessments}

The criteria described in this section define the essential categories for the success of any written task. Written activities are evaluated based on these elements, each of which must fulfill a specific function to support the overall effectiveness of it. Depending on the assignment, particular criteria may be weighted more than others, and the instructor's task may establish additional, more specific standards (Brown \& Abeywickrama, 2010).

In this study, the evaluation criteria for the written activities were: content, creativity, mechanics, and neatness. A brief description of these criteria is presented below.

Content is the key to writing to connect with readers. It encompasses other elements of writing such as creativity, grammar, vocabulary, coherence, etc. (Bae, Bentler, \& Lee, 2016). Good content can draw attention to any texts that have been produced making readers eager to learn what the writing piece topic is about (Bae et al., 2016).

Creativity demonstrates the ability to use relevant skills to produce ideas conveyed in texts that are unique and original (Humphrey, Walton, \& Davidson, 2014; Sundeen, 2014). Creativity helps to create a connection between students and the task, allowing them to express ideas as they need or want.

Mechanics refers to all the standard technical rules in writing. In other words, is the term we use to describe the technical aspects of writing, such as spelling, punctuation, capitalization, etc.

- Spelling is "The conventions which determine how the graphemes of a writing system are used to write a language" (Coulmas, 1996, p. 477). Spelling refers to alphabetic or phonetic writing systems. It describes the order in which letters are placed in a word. In English, words generally have accepted standard spellings which can vary regionally or nationally. 
Also, spelling is one of the elements of orthography and a regulatory component of alphabetic languages (Coulmas, 1996).

- Punctuation is the conventional system that uses symbols to help people read and process sentences the way they are meant to be heard and understood (Wikoff, 2018). Therefore punctuation uses conventional marks to separate ideas assisting writers and readers understand the meaning of what is being communicated and provide pace and rhythm to sentences, phrases, and paragraphs (Coulmas, 2003).

- Capitalization refers to capital letters are used for two primary purposes in English: to show the beginning of a sentence, to differentiate proper from common nouns, etc.

- Grammar includes principles that guide the structure of sentences and paragraphs, and because grammar involves the way it structured sentences, this category consists of the eight "parts" of "speech": nouns, verbs, pronouns, adverbs, adjectives, prepositions, conjunctions, and interjections.

- Style. Writing styles encompass many different aspects or components. However, three of the main elements are word choice, sentence fluency, and voice (Lumen Learning, 2019).

- Word choice. Avoiding the use of superfluous words is essential for good writers. Writing concisely and accurately, choosing the ideal word to communicate the desired idea (Humphrey et al., 2014; Lumen Learning, 2019) is paramount in quality writing (Lumen Learning, 2019). Specific and suitable words, together with active verbs, concrete nouns and precise adjectives help writers to convey their ideas and readers picture what is being communicated. Good writers use qualifiers carefully and adverbs rarely, allowing nouns and verbs to carry out the work (Lumen Learning, 2019).

- Sentence fluency refers to the flow and rhythm words also transmitted to sentences, phrases, and paragraphs. Using a variety of sentences with various lengths and rhythms are essential to convey different effects to readers. The analogous use constructions in sentences and paragraphs are typical to reproduce similar ideas, but also to avoid flatness by changing sentence structures (Lumen Learning, 2019).

- Voice helps readers to learn about the writer's personality. "A writer's voice can be impersonal or chatty, authoritative or reflective, objective or passionate, serious or funny" (Lumen Learning, 2019).

Neatness is a critical component of writing. Neat handwriting is usually an indication of functional organizational abilities. People often think that individuals with untidy unreadable handwriting must be disorganized in other aspects of their lives as well (Oxford Learning 
Centres, 2006). Overall writing presentation demonstrates students' effort on their tasks (Oxford Learning Centres, 2006).

\section{Methods}

The present study was carried out at Unidad Educativa Colegio Militar $\mathrm{N}^{\circ} 6$ "Combatientes de Tapi (UECMCT), Riobamba, Ecuador. The study was carried out during the school year 2014-2015. In Ecuador, the school system divides school years, in elementary education, into two five-month periods known as quimesters. Twenty-eight students of eighth grade, classroom " $D$ " (octavo año de educación básica class "D") and ten foreign language teachers participated in the study. The data collection was performed in four consecutive stages:

\section{Stage one}

Although the focus of this study was on the influence of rubrics over students' academic performance, firstly a diagnostic survey was applied to foreign language teachers working at UECMCT, to learn about the assessment tools they use for evaluation. Ten teachers answered a questionnaire which contained six questions. The questions had three response options: Always, Sometimes and Never.

\section{Stage two}

The second stage lasted two months. It determined students' academic performance through an in-class writing assessment during the second term of the second Quimester. Only the final product, "My family scrapbook," was evaluated without using a rubric neither establishing any criteria to perform and assess the written activity.

\section{Stage three}

The last stage consisted of data collection from the assessment of the written activity after the application of a rubric. The evaluation procedure was explained to the students. The qualities of good and poor work by listing the pre-establish criteria in the development of the written activity "My family scrapbook." The criteria applied to perform the written activity assessed content, mechanics, creativity, and neatness, according to the scale noted below:

- Excellent

$2.5 / 2.5$

- Good $2 / 2.5$

- Average $1.5 / 2.5$

- Weak 1/ 2.5 


\section{Stage Four}

Finally, to identify whether the implementation of rubrics as an assessment tool influences students' academic performance on the Foreign Language subject, the results of the student's performance before and after the application of rubrics were compared and analyzed. The scale used for the analysis of the influence of the use of the rubric on students' academic performance is presented below:

- Does not reach the learning required

- Close to reaching the learning required

- Reach the learning required

- Dominates the learning required

\section{Results}

Results of the survey applied to foreign language teachers at the Unidad Educativa Colegio Militar N6 "Combatientes de Tapi.

Considering that rubrics are essential assessment tools among teachers, particularly in foreign language teaching, this study started with the application of a diagnostic survey questionnaire to the institution's English Language teachers $(n=10)$ to identify which assessment tools were typically used by them. The questionnaire contained six questions which had three response options. The results of the survey applied to teachers are shown in figure 1 .

\section{Results of Survey Applied to English Language Teachers}

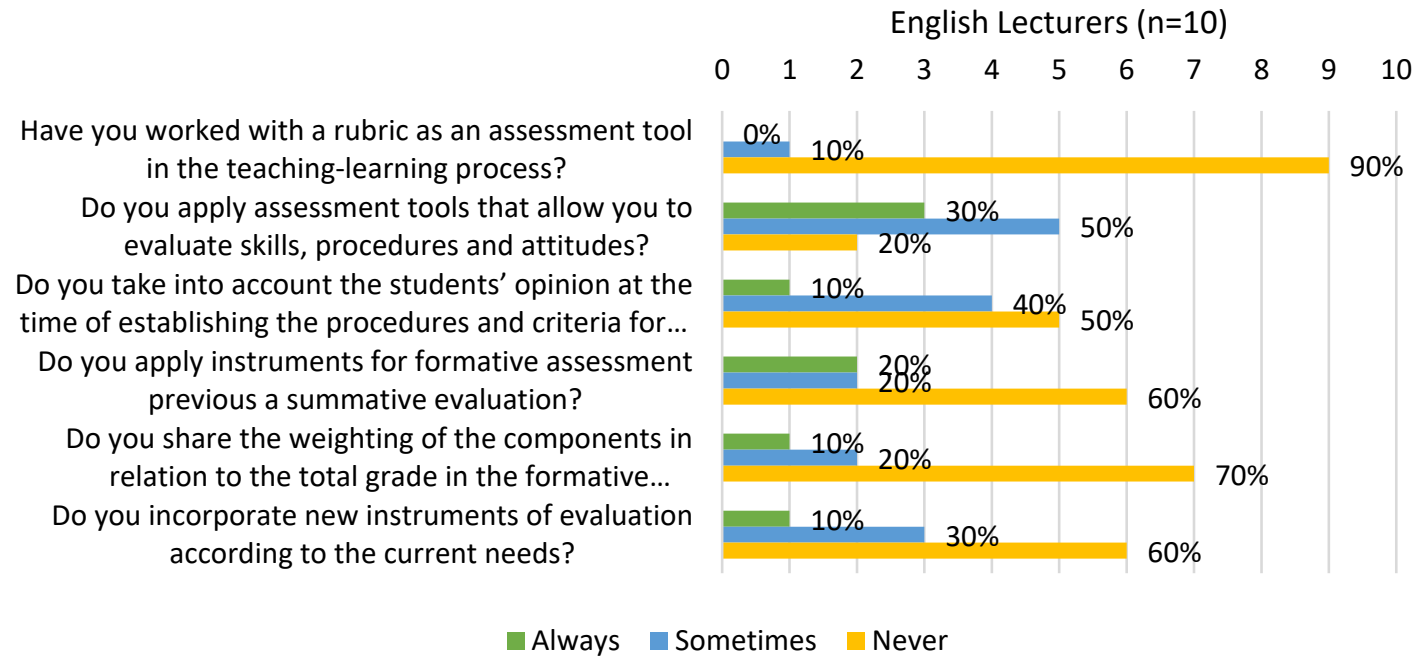

Figure 1. Results of survey applied to foreign language teachers 
Unexpectedly, nine out of ten surveyed teachers (90\%) answered that they had never worked with a rubric as an assessment tool, in the learning process while one teacher (10\%) stated that he/she used a rubric sometimes. Also, the results show that (70\%) of the teachers never share the weighting of the assessment components about the total grade with the students. And, six out of ten $(60 \%)$ of teachers never apply instruments for formative evaluations before a summative one, nor incorporate new evaluation instruments according to the current needs. These results suggest that Foreign Language Teachers at Unidad Educativa Colegio Militar No6 "Combatientes de Tapi, at the time of this study, were not using adequate assessment tools.

\section{Writing rubric's assessment criteria rubric applied to students}

The writing criteria applied to the students of eighth grade, classroom " $D$ " at Unidad Educativa Colegio Militar No6 "Combatientes de Tapi," during the second term of the second quimester comprised four factors: content, mechanics, creativity, and neatness. Those rubric's components were assessed using the scale detailed below:

- Excellent

- Good

- Average $1.5 / 2.5$

- Weak $1 / 2.5$

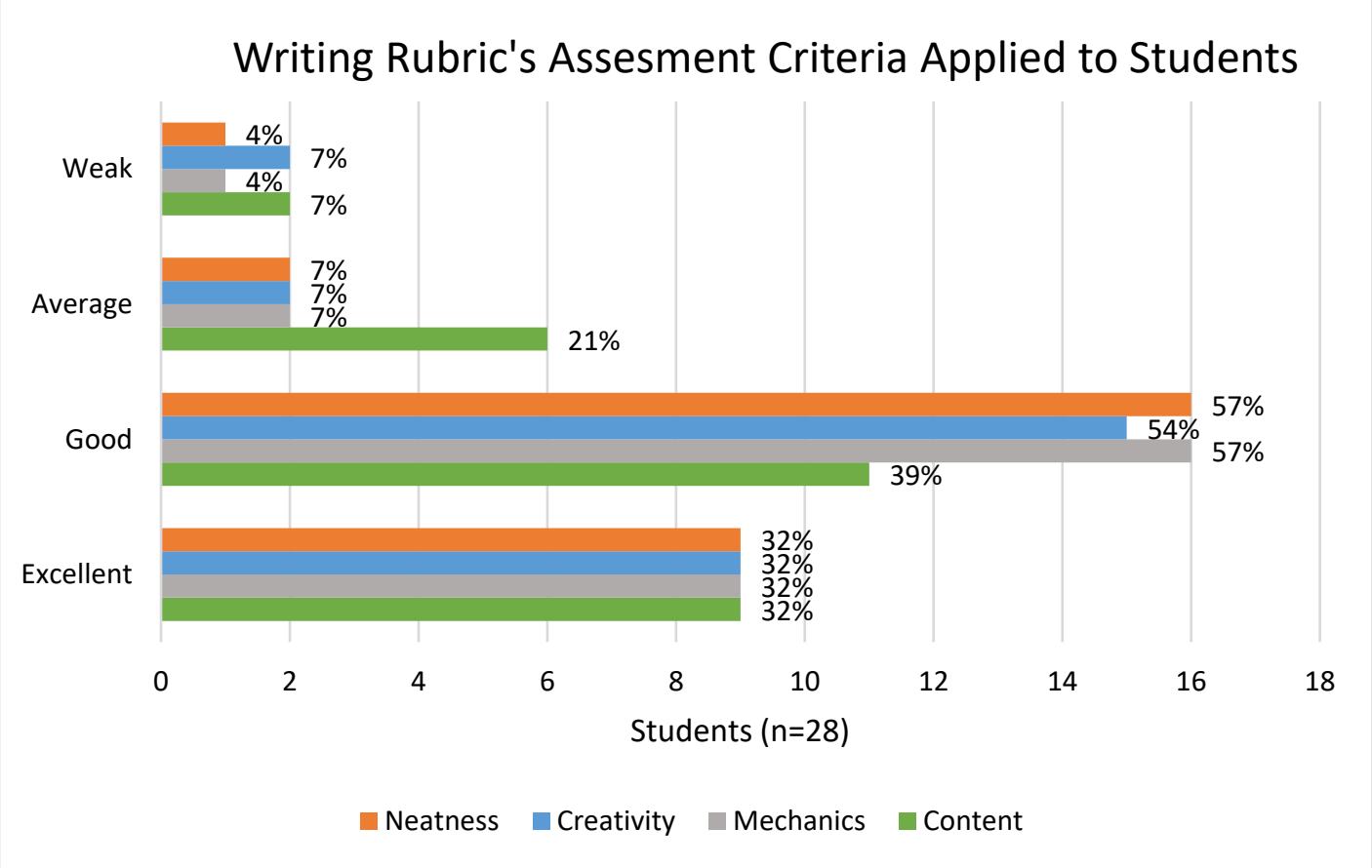

Figure 2. Writing rubric's assessment criteria applied to students 
The results show that, once the rubric was implemented, $32 \%$ of the students obtained an excellent mark on all the components assessed comprised in the rubric, i.e., content, mechanics, creativity, and neatness. Also, over half of the students achieved a good score on mechanics and neatness, along with creativity, where over half of the students reached a good mark. Conversely, around $10 \%$ of the students assessed achieved either an average or weak score on the factors evaluated through the rubric.

\section{Student's academic performance before the application of writing rubrics}

To identify whether the use of rubrics influence students' academic performance of the students of eighth grade, classroom "D" at Unidad Educativa Colegio Militar No6 "Combatientes de Tapi," data on the assessment of the writing task was collected through the teachers' academic reports during the second term of the second quimester. The grades reached by the students were classified into using four categories according to the scale detailed below:

- Dominates the learning required

$9.00-10.00$

- Reaches the level of learning required

$7.00-8.99$

- Close to achieve the learning required

$3.99-6.99$

- Does not reach the learning required

0.00-3.99

\section{Students' Academic Performance Before the Application of Rubrics}

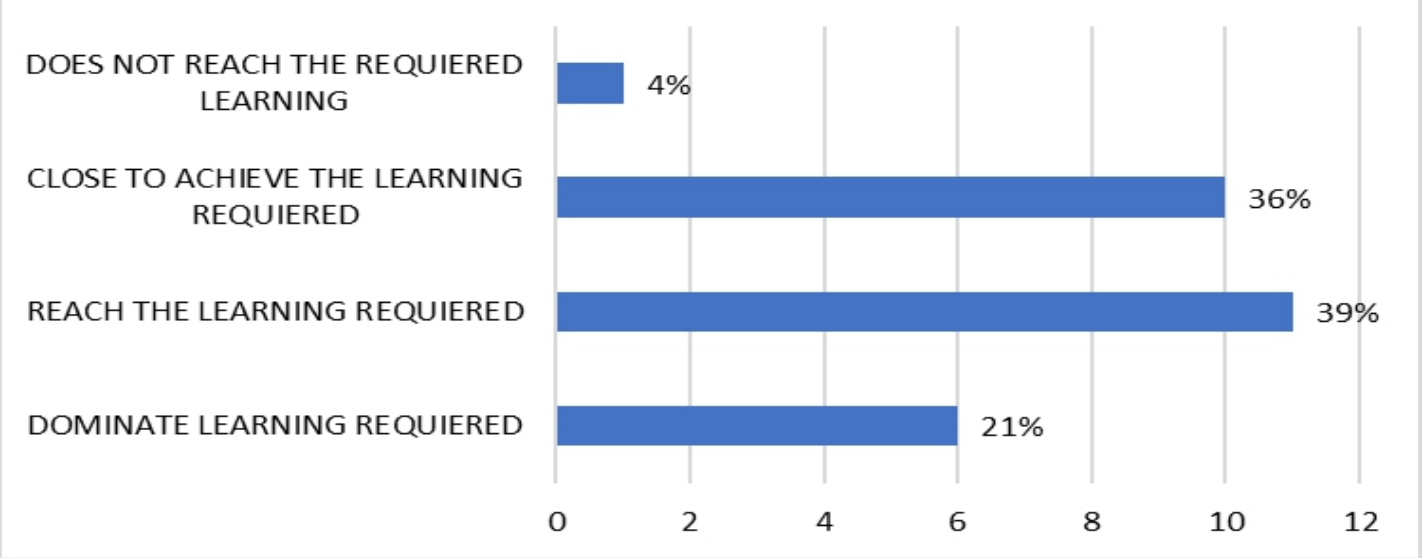

Figure 3. Student's academic performance before the application of writing rubrics

The results (Figure 3) concerning students' academic performance show that before the implementation of a rubric, $4 \%$ of the students who participated in the study did not reach the level of learning required, while 
$36 \%$ of them were close to achieve the learning required. However, 39\% of the students reached the learning required, and $21 \%$ dominated the learning required.

\section{Students' academic performance after the application of writing rubrics}

To identify whether the application of rubrics influence students' academic performance of the students of eighth grade, classroom " $D$ " at Unidad Educativa Colegio Militar N 6 "Combatientes de Tapi," data on the assessment of the writing task was collected through the teachers' academic reports during the third term of the second quimester. The grades reached by the students were classified into using four categories according to the scale detailed below:

- Dominates the learning required

$9.00-10.00$

- Reaches the level of learning required

- Close to achieve the learning required

- Does not reach the learning required 0.00-3.99

\section{Student's Academic Performance after the Application of Rubrics}

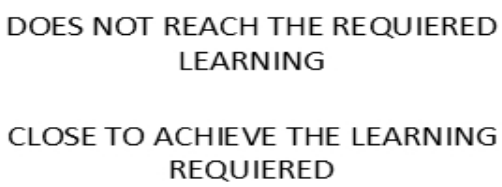

REACH THE LEARNING REQUIERED

DOMINATE LEARNING REQUIERED

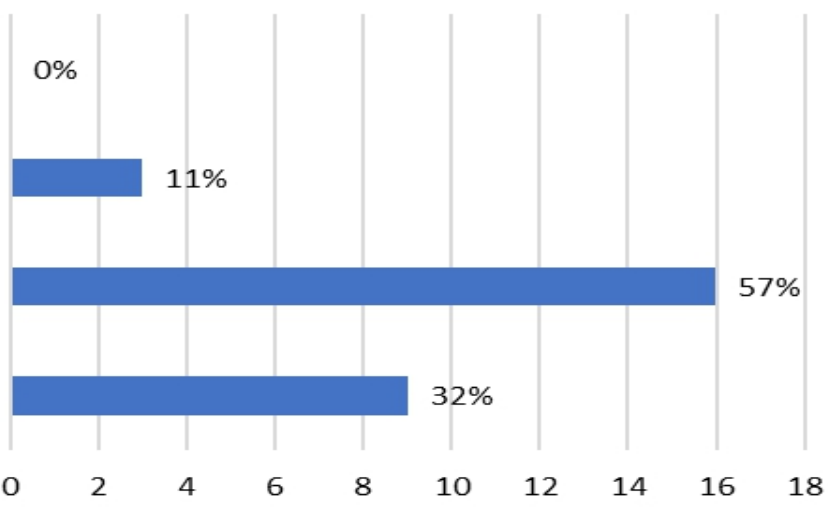

Figure 4. Student's academic performance after the application of writing rubrics

The results concerning students' academic performance after the implementation of a writing rubric show a significative improvement. Interestingly, 57\% of the students reached the level of learning required and $32 \%$ dominated the learning required. Conversely, there were no students $(0 \%)$ who did not reach the required learning, and $11 \%$ of students were close to achieve the required learning. 


\section{Students' academic performance before and after the application of rubrics}

\section{Students' Academic Performance before and after the application of rubrics}

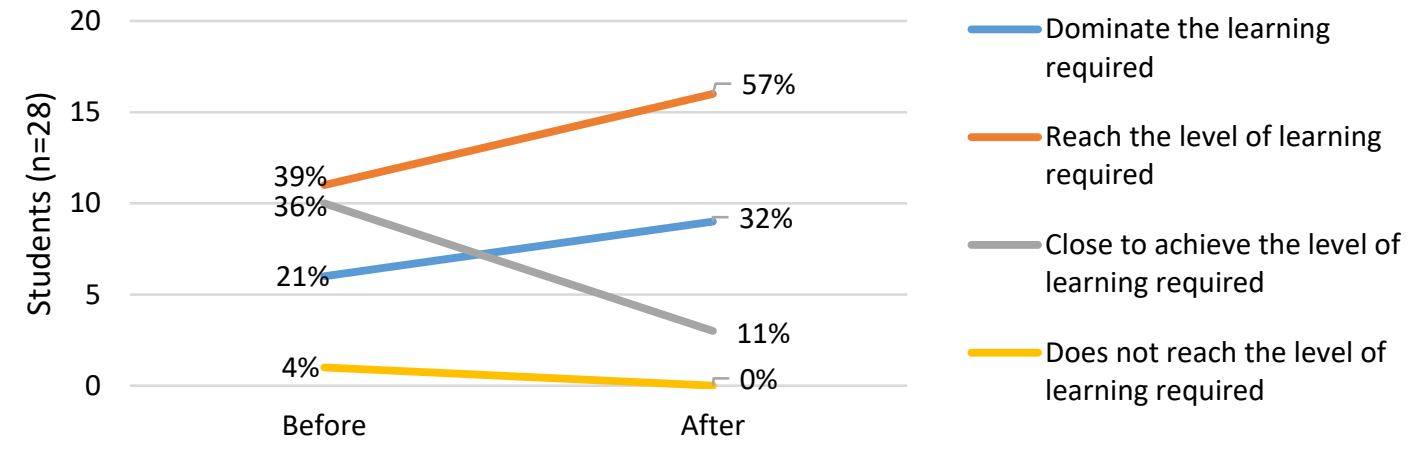

Figure 5. Students' academic performance before and after the application of rubrics

Students' academic performance increased after the application of rubrics. Figure 5 shows that the percentage of students that dominated the learning required went from $21 \%$ to $32 \%$, while the percentage of students who reached the level of learning required rose from $39 \%$ to $57 \%$. Conversely, the percentage of students that before the application of the rubric was close to achieve the level of learning required dropped from $36 \%$ to $11 \%$ and the component does not reach the level of learning required experienced a reduction of four percentage points from $4 \%$ to $0 \%$.

\section{Conclusion}

This study adds on the literature about the influence of rubrics over students' academic performance. Rubrics are favorite assessment tools among foreign language teachers (Dickinson \& Adams, 2017; Fraile et al., 2017; Stiggins \& Chappuis, 2005). They provide specific criteria for students' evaluation (Dawson, 2017; Dickinson \& Adams, 2017; Janssen et al., 2015) and facilitate the process of assessment and reporting of student achievement by educators (Glickman-Bond \& Rose, 2006; Reddy, 2007). It was hypothesized that sharing and explaining the elements of a rubric to students before a written assignment would improve the task product quality. The analysis of students' evaluation collected before and after the application of a rubric for writing showed a significant improvement in academic performance when a rubric was used. Most students after the application of a rubric either reached or dominated the learning required. These results support the hypothesis that using an instructional rubric to teach students the expectations for the writing assignment before administering a test improves the quality of 
student writing. Similar results were also reported by Sundeen (2014). Also, this paper shows that, in the case of this investigation, Foreign Language teachers not usually employ rubrics as an assessment tool in their academic tasks. Considering the results of this investigation, it is highly recommended to adopt and incorporate the use of rubrics in the teaching-learning process, to help students in comprehending what is expected from their writing assignments. Furthermore, as shown in this article, using rubrics for written activities can effectively assist students in improving their academic performance.

\section{References:}

1. Alves-Martins, M., Peixoto, F., Gouveia-Pereira, M., Amaral, V., \& Pedro, I. (2002). Self-esteem and Academic Achievement Among Adolescents. Educational Psychology, 22(1), 51-62. doi:10.1080/01443410120101242

2. Bae, J., Bentler, P. M., \& Lee, Y.-S. (2016). On the Role of Content in Writing Assessment. Language Assessment Quarterly, 13(4), 302-328. doi:10.1080/15434303.2016.1246552

3. Black, P. J., \& Wiliam, D. (1998). Raising standards through classroom assessment: King's College London, School of Education.

4. Brookhart, S. M. (2003). Developing measurement theory for classroom assessment purposes and uses. Educational measurement: Issues and practice, 22(4), 5-12.

5. Brown, H. D., \& Abeywickrama, P. (2010). Language assessment: principles and classroom practices (2nd ed.). White Plains, NY: Pearson Education.

6. Coulmas, F. (1996). The Blackwell encyclopedia of writing systems: Blackwell Oxford.

7. Coulmas, F. (2003). Writing systems: An introduction to their linguistic analysis: Cambridge University Press.

8. D’Alessio, F. A., Avolio, B. E., \& Charles, V. (2019). Studying the impact of critical thinking on the academic performance of executive MBA students. Thinking Skills and Creativity, 31, 275-283. doi:https://doi.org/10.1016/j.tsc.2019.02.002

9. Dawson, P. (2017). Assessment rubrics: towards clearer and more replicable design, research and practice. Assessment \& Evaluation in Higher Education, 42(3), 347-360.

10. Dickinson, P., \& Adams, J. (2017). Values in evaluation - The use of rubrics. Evaluation and Program Planning, 65, 113-116. doi:https://doi.org/10.1016/j.evalprogplan.2017.07.005

11. Fraile, J., Panadero, E., \& Pardo, R. (2017). Co-creating rubrics: The effects on self-regulated learning, self-efficacy and performance of 
establishing assessment criteria with students. Studies in Educational Evaluation, 53 , 69-76. doi:https://doi.org/10.1016/j.stueduc.2017.03.003

12. Glickman-Bond, J., \& Rose, K. (2006). Creating and using rubrics in today's classrooms: A practical guide: Christopher-Gordon Publishers.

13. Glossary of Education Reform. (2014, 8/23/2013). Rubric. Retrieved from https://www.edglossary.org/rubric/

14. Hoy, A. W. (2007). Educational psychology (10th ed.). Boston, Mass;London;: Pearson.

15. Humphrey, R. C., Walton, M. D., \& Davidson, A. J. (2014). “Im Gonna Tell You All About It": Authorial Voice and Conventional Skills in Writing Assessment and Educational Practice. The Journal of Educational Research, 107(2), 111-122. doi:10.1080/00220671.2013.788990

16. Janssen, G., Meier, V., \& Trace, J. (2015). Building a better rubric: Mixed methods rubric revision. Assessing Writing, 26, 51-66. doi:https://doi.org/10.1016/j.asw.2015.07.002

17. Lumen Learning. (2019). English Composition I. Style. Retrieved from https://courses.lumenlearning.com/engcomp1wmopen/chapter/text-style/

18. Mianto, E. (2012). Using Rubrics to test student's performance in Speaking. Retrieved from https://www.academia.edu/2205164/using_rubrics_to_test_students_ performance_in_speaking

19. Mushtaq, I., \& Nawaz Khan, S. (2012). Factors affecting student's performance. Global Journal of Management and Business, 12(9).

20. Oxford Learning Centres. (2006, October 11, 2006). Handwriting skills: Neatness counts! Retrieved from https://www.oxfordlearning.com/handwriting-skills-neatness-counts/

21. Panadero, E., Alonso-Tapia, J., \& Reche, E. (2013). Rubrics vs. selfassessment scripts effect on self-regulation, performance and selfefficacy in pre-service teachers. Studies in Educational Evaluation, 39(3), 125-132. doi:10.1016/j.stueduc.2013.04.001

22. Panadero, E., \& Jonsson, A. (2013). The use of scoring rubrics for formative assessment purposes revisited: A review. Educational Research Review, 9, 129-144. doi:https://doi.org/10.1016/j.edurev.2013.01.002

23. Reddy, M. Y. (2007). Effect of rubrics and the enhancement of student learning. Educate , 7(1), 3-17.

24. Regier, J. (2011). Why is academic success important? Saskatchewan School Boards Association. 
25. Santos, F. R. (1998). Género, redes de amistad y rendimiento académico [Redes sociales, Exito académico]. Revista de sociología (56), 233-242.

26. Steinmayr, R., Meiǹer, A., Weideinger, A. F., \& Wirthwein, L. (2014). Academic achievement. In: Oxford University Press.

27. Stiggins, R., \& Chappuis, J. (2005). Using student-involved classroom assessment to close achievement gaps. Theory into practice, 44(1), 1118.

28. Sundeen, T. H. (2014). Instructional rubrics: Effects of presentation options on writing quality. Assessing Writing, 21, 74-88. doi:https://doi.org/10.1016/j.asw.2014.03.003

29. Wikoff, K. (2018, January 29, 2019). What's the difference between grammar, punctuation, and mechanics? Retrieved from https://katherinewikoff.com/2012/10/18/whats-the-differencebetween-grammar-punctuation-and-mechanics/

30. York, T. T., Gibson, C., \& Rankin, S. (2015). Defining and Measuring Academic Success. Practical Assessment, Research \& Evaluation, 20. 